\title{
Impact of Intensive Phototherapy on Neurological State of Neonates with Severe Hyperbilirubinemia
}

\author{
Ahmed Mahmoud Abd Elmoktader ${ }^{(1)}$, Ashraf Sayed Kamel ${ }^{(2)}$, Sherin Khamis Hussein ${ }^{(3)}$ \\ and Ali Hassan Mahmoud ${ }^{(4)}$. \\ (1) Professor of Pediatrics and neonatology, Faculty of Medicine, Fayoum University. \\ (2) Assisstant Professor of Pediatrics, Faculty of Medicine, Fayoum University . \\ (3) Lecturer of Pediatrics, Faculty of Medicine, Fayoum University . \\ (4) (M.B.B.Ch), Resident of Pediatrics in Fayoum Health Insurance hospital.
}

Corresponding author: Dr. Ahmed Mahmoud Abd Elmoktader, E-mail: ama13@fayoum.edu.eg

Fax: 0846302350

Tel: 0846300587

\begin{abstract}
Neonatal hyperbilirubinemia is a leading cause of morbidity and mortality in developing countries with adverse consequences occur as neonatal mortality, cerebral palsy, isolated auditory impairment, and a diverse manifestation of subtle processing disorders because of bilirubin-induced use of intensive neurologic dysfunction (BIND). In severe and rapidly increasing jaundice, the greater effectiveness and a faster decrement in bilirubin level. phototherapy provides

This is a prospective study conducted on 40 neonates with severe hyperbilirubinemia admitted to NICU at Fayoum University Hospital, Faculty of Medicine, Fayoum University, Egypt in the period between April 2017 to October 2017. All newborns are subjected to intensive phototherapy (Bilisphere 360) and BIND score was assessed before and after administration of intensive phototherapy.
\end{abstract}

Our study showed that $55 \%$ of babies were mild BIND, $40 \%$ were moderate and only $5 \%$ with severe BIND (before bilisphere). While $97.5 \%$ became normal BIND and $2.5 \%$ were moderate BIND (after bilisphere).

\section{KEYWORDS: BIND score, Hyperbilirubinemia, Intensive phototherapy.}

\section{INTRODUCTION:}

Neonatal jaundice is defined as yellowish discoloration of skin, sclera of eyeball, and mucous membranes caused by deposition of bile in these tissues (1).

Globally, health care providers worldwide recognize that severe neonatal jaundice is a "silent" cause of significant neonatal morbidity and mortality. Untreated neonatal jaundice can lead to death in the neonatal period and to kernicterus, a major cause of neurologic disability (choreo-athetoid cerebral palsy, deafness and language difficulty) in children who survive this largely preventable neonatal problem (2).
BIND score is the score of onset, severity and progression of acute bilirubin encephalopathy in infants with hyperbilirubinemia (total serum bilirubin >95thpercentile for age in hours). The simplicity of the BIND scoring system, similar to the Apgar score, makes it an attractive tool for clinical diagnosis of $\mathrm{ABE}$ in resource limited locations that lack ready access to MRI and ABR (3).

Intensive phototherapy in neonatal hyperbilirubinemia rapidly decreases total serum bilirubin (TSB) below the threshold for exchange transfusion (4). 
Bilisphere is a novel neonatal phototherapy device designed to provide blue

\section{AIM OF THE WORK:}

To evaluate the effectiveness of intensive phototherapy on bilirubin induced neurological dysfunction (BIND) score in neonates with severe hyperbilirubinemia

\section{PATIENTS AND METHODS:}

This study was conducted on 40 neonates with severe hyperbilirubinemia admitted to NICU at Fayoum University Hospital, Egypt in the period between April 2017 to October 2017.The study was included neonates with severe hyperbilirubinemia necessitating intensive phototherapy.

\section{Inclusion criteria:}

Any newborn admitted with severe jaundice fulfilling the following data:

1. Gestational age $\geq 36$ wks.

2. TSB $\geq 20 \mathrm{mg} / \mathrm{dl}$.

\section{Exclusion criteria:}

- Congenital life threatening conditions e.g.; Birth defect and Congenital malformation.

- Acquired life threatening conditions e.g.; shock, respiratory failure and post arrest.

Oral consents were obtained from parents or caregivers then all the neonates light illumination to the whole of a baby's skin surface with high irradiance (5).

(effectiveness on decreasing acute bilirubin encephalopathy), and minimizing the need for exchange transfuion. included in the study were subjected to the following:

A) Detailed History was taken with special regards to : Maternal history:

- family history of neonatal jaundice. Perinatal History:

- Antenatal: gestational age.

- Natal: mode of delivery.

- Postnatal: age, sex and weight on admission.

\section{B)Examination:}

- Neurological examination was performed during the stay in our hospital every 8 hours.

- Assessment of BIND score depends on :

- mental status.

- muscle tone.

- cry pattern of the neonates.

- This score was done before and after intensive phototherapy.

\section{Table(16): Bilirubin-Induced Neurological Dysfunction (BIND) Score}

\begin{tabular}{|l|l|l|}
\hline Parameter & Finding & Points \\
\hline \multirow{5}{*}{ Cry pattern } & Normal & 0 \\
\cline { 2 - 3 } & High pitced & 1 \\
\cline { 2 - 3 } & Piercing, shrill, frequency decreased or increased & 2 \\
\cline { 2 - 3 } & Inconsolable or cries only with stimulation & 3 \\
\hline \multirow{5}{*}{ Buscle tonavioural and mental status } & Normal & 0 \\
& Sleepy, poor feeding & 1 \\
\cline { 2 - 3 } & Lethargy, very poor feeding, irritable & 2 \\
\cline { 2 - 3 } & Semicoma , intermittent apnea , seizures & 3 \\
\hline & Normal & 0 \\
\cline { 2 - 3 } & Variable hypotonia & 1 \\
\cline { 2 - 3 } & $\begin{array}{l}\text { Moderate hyper or hypotonia , posturing, bicycling } \\
\text {,nuchal or truncal arching }\end{array}$ & 2 \\
\cline { 2 - 3 } & Severe hyper or hypotonia , opisthotonus & 3 \\
\hline
\end{tabular}


BIND score $=$ sum (points for all 3 parameters).

Score of 7 to 9: represent severe acute bilirubin encephalopathy; urgent interventions are recommended to possibly minimize further brain injury.

Scoreof4 to 6: represent moderate acute bilirubin encephalopathy and is likely to be reversible with urgent bilirubin reduction.

Scores of 1 to 3: represent mild acute bilirubin encephalopathy and are usually reversible with urgent bilirubin reduction strategies.

\section{C) Laboratory Investigation:}

- Serum total bilirubin and direct bilirubin on admission and repeated after 8 hours.

- Hemoglobin, reticulocytic count, Blood group ( $\mathrm{ABO}$, RH grouping ) of the infant and mother.

\section{D) Interventions:}

All patients was subjected to intensive phototherapy (Bilisphere).

\section{Statistical analysis}

Data were collected, coded, revised and entered to the Statistical Package for Social Science (IBM SPSS) version 20. The data were presented as number and percentages for the qualitative data, mean, standard deviations and ranges for the quantitative data with parametric distribution and median with inter quartile range (IQR) for the quantitative data with non parametric distribution.

Paired t-test was used in the comparison between two groups with quantitative data for before and after and parametric distribution and Wilxon Rank test are used in the comparison between two groups with quantitative data for before and after and non parametric distribution.

The confidence interval was set to $95 \%$ and the margin of error accepted was set to $5 \%$. So, the p-value was considered significant as the following:

$\mathrm{P}>0.05$ : Non significant (NS)

$\mathrm{P}<0.05$ : Significant $(\mathrm{S})$

$\mathrm{P}<0.01$ : Highly significant (HS)

\section{RESULTS}

Table (1): TSB at Admission and After 8 hr.

\begin{tabular}{|l|l|l|l|l|}
\hline & Min & Max & Mean & SD \\
\hline TSB at admission & 20 & 38,1 & 25,49 & 4,78 \\
\hline TSB after 8hr & 13,5 & 30 & 19,95 & 4,27 \\
\hline
\end{tabular}

Table (2): BIND Score Before and After Bilisphere.

\begin{tabular}{|l|l|l|l|}
\hline \multicolumn{5}{|c|}{} & No. & \% \\
\hline \multirow{5}{*}{ BIND before bilisphere } & Mild & 22 & $55,0 \%$ \\
\cline { 2 - 4 } & Moderate & 16 & $40,0 \%$ \\
\cline { 2 - 4 } & Severe & 2 & $5,0 \%$ \\
\cline { 2 - 4 } & Mean \pm SD & 3,58 & 1,50 \\
\cline { 2 - 4 } & Range & 1 & 8 \\
\hline \multirow{5}{*}{ BIND after bilisphere } & normal & 39 & $97,5 \%$ \\
\cline { 2 - 4 } & Moderate & 1 & $2,5 \%$ \\
\cline { 2 - 4 } & Mean \pm SD & 0,38 & 1,03 \\
\cline { 2 - 4 } & Range & 0 & 6 \\
\hline
\end{tabular}


Table (3): Need for Exchange Transfusion.

\begin{tabular}{|l|l|l|l|}
\hline \multicolumn{2}{|c|}{} & No. & $\%$ \\
\hline \multirow{3}{*}{ Exchange transfusion } & No & 29 & $72,5 \%$ \\
\cline { 2 - 5 } & Yes & 11 & $27,5 \%$ \\
\hline
\end{tabular}

Table (4): Comparison Between TSB and BIND Score Before and After Bilisphere.

\begin{tabular}{|l|l|l|l|l|l|l|}
\hline \multirow{2}{*}{} & \multicolumn{3}{|l|}{ Before } & \multicolumn{2}{l|}{ After } & \multicolumn{2}{l|}{ Paired t test } \\
\cline { 2 - 8 } & Mean & SD & Mean & SD & t & P value \\
\hline TSB & 25,49 & 4,78 & 19,95 & 4,27 & 14,142 & $<0.001$ \\
\hline BIND score & 3,58 & 1,50 & 0,38 & 1,03 & 19,41 & $<0.001$ \\
\hline
\end{tabular}

Figure (1): TSB Before and After Bilisphere

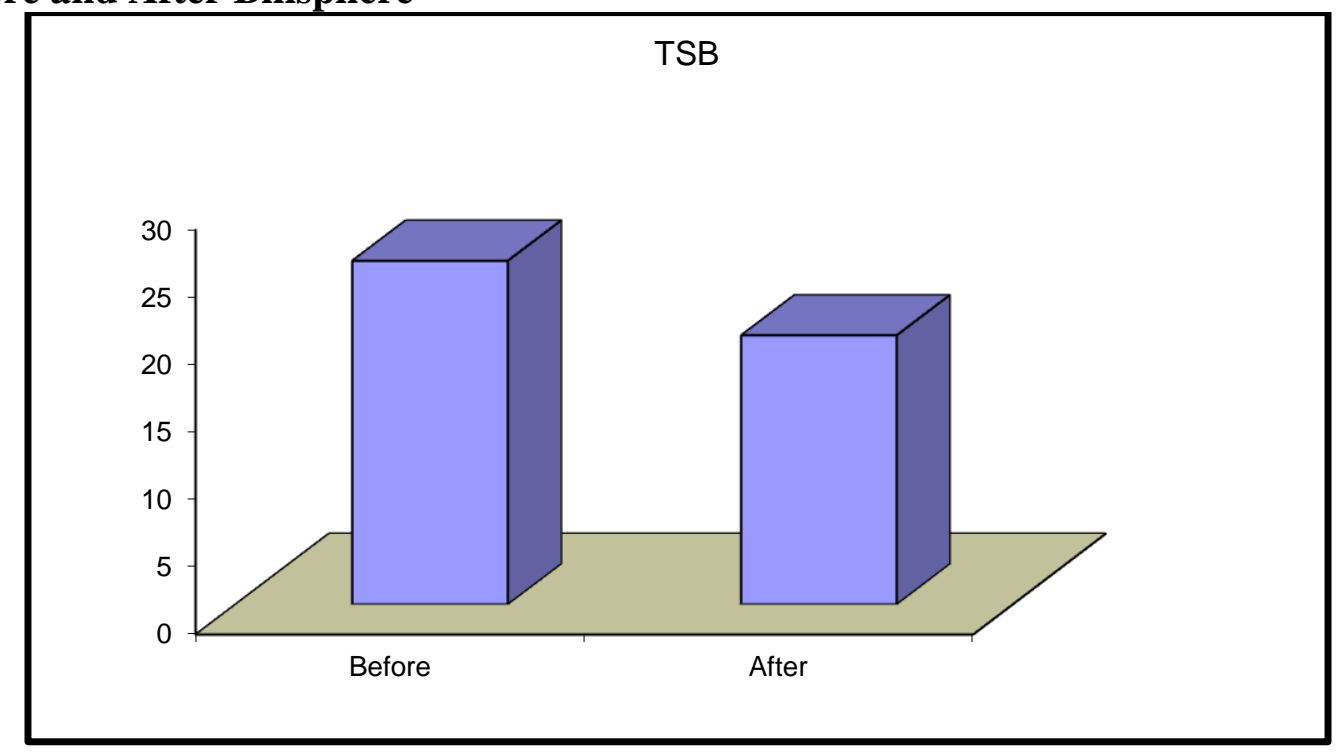

Figure (2): BIND Score regarding Before and After Bilisphere

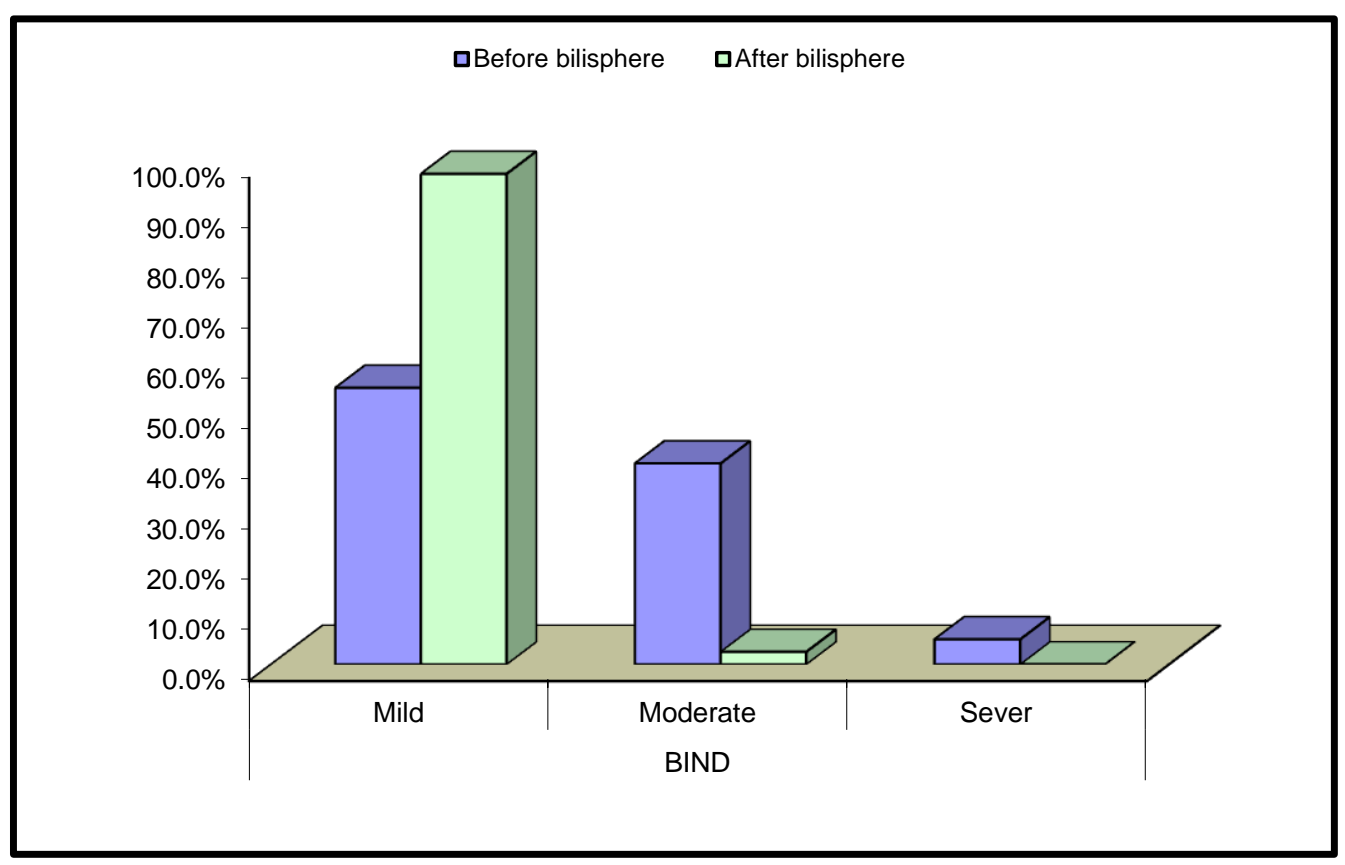




\section{DISCUSSION:}

In the current study we found that the mean of total serum bilirubin at admission was 25.49 with range from 20 to 38.1 . This in agreement with the study conducted by AbdelLatif et al., in 2012 (6) that showed the mean TSB on admission for all the cases was $26.8 \pm 6.2 \mathrm{mg} / \mathrm{dL}$, also the study conducted by Iskander et al., in 2014 (7), the mean total bilirubin at admission was $25.76 \pm 4.39$ $\mathrm{mg} / \mathrm{dL}$. Disagreement with our results the study conducted by Davutoglu et al., in 2010 (8), as the mean peak total bilirubin level was $28.1 \pm 6.4 \mathrm{mg} / \mathrm{dL}$.

Results of this study showed that the rate of decline of TSB was $0.92 \mathrm{mg} / \mathrm{dl} / \mathrm{hr}$ after 6-8hrs. Similar to our study De Carvalho et $\boldsymbol{a l}$., in 2011 (9), found that the rate of decline of TSB was $0.8 \mathrm{mg} / \mathrm{dl} / \mathrm{hr}$ after 6 hours. Also Al-Hafidh et al., in 2013 (10) found that the rate of decline was $0.81 \pm 0.38 \mathrm{mg} / \mathrm{dl} / \mathrm{hr}$. While Umran, in 2012 (11), reported that the reduction rate of total serum bilirubin was 1.3 $\mathrm{mg} / \mathrm{dl} / \mathrm{hr}$. Also Abd-Ellatif et al., in 2012 found that the mean rate of TSB declined during stay in the bilisphere was 1.19 $\mathrm{mg} / \mathrm{dl} / \mathrm{hr}$.

Bilirubin induced neurological dysfunction (BIND) score was performed to all neonates in our study at admission and after 6-8 $\mathrm{hr}$ of intensive phototherapy. Neonates with BIND scores 1-3 represent cases with mild acute bilirubin encephalopathy, scores 46 represent cases with moderate acute bilirubin encephalopathy, while score 7-9 represent cases with severe acute bilirubin encephalopathy.

Our study showed that neonates with BIND score 1-3 (mild) in 55\%, BIND score 46 (moderate) in $40 \%$, while $5 \%$ of neonates have BIND score more than 6 (severe affection). After intensive phototherapy, neonates with mild and moderate BIND show normal BIND (97.5\%). Neonates with severe BIND score (of 7-9) had persistent evidence of $\operatorname{BE}(2.5 \%)$. Similar to our results
Gamaleldin et al., in 2011 (12) found that most of their neonates with neonatal hyperbilirubinemia had BIND score mild on admission in $(60 \%)$, BIND score moderate in $32 \%$ neonates and only $8 \%$ had BIND score more than 6 (sever affection).

In the current study all neonates have intensive phototherapy and $27.5 \%$ (11 newborns) of them needed single exchange transfusion. In contrast to this, Steiner et al., in 2007 (13) measured the efficacy of phototherapy in reduction of exchange transfusions in NICU and they found that only 2.8\% (3 newborns) from 107 newborns required exchange transfusion. Also, $\boldsymbol{A} \boldsymbol{b} \boldsymbol{d}$ Ellatif et al., in 2012 found that exchange blood transfusion was performed in 13 newborns out of 212 with extreme hyperbilirubinemia. This difference from our results could be explained due to their prolonged duration of intensive phototherapy $(35.4 \pm 19.5)$ hours, compared to our duration (6-8 hours) and the greater number of babies than ours (40 newborns). Also Al-Hafidh et al., in 2013 found that exchange transfusion was not required in their study after intensive phototherapy. This difference can be explained by their lower initial TSB levels $(18.85 \pm 4.57 \mathrm{mg} / \mathrm{dl})$ compared than our levels.

\section{Recommendations}

- Start intensive phototherapy in cases with level near that of exchange transfusion before taking the decision of exchange transfusion.

- Long term follow up trials should be performed to evaluate the development of newborns with severe hyperbilirubinemia treated with intensive phototherapy.

- BIND score should be used as a follow up measure for all cases with neonatal hyperbilirubinemia. 


\section{REFERENCES}

[1] Irshad M, Mohammaed A, Hussain M, Hayat M, Khan B, Ahmad A, Karim R and Ali N (2011):Prevalence of Rhesus type and ABO incompatibility in jaundiced neonates,Indian journal of public health.vol 25 no 03:233-239.

[2] Slusher TM and OlusanyaO (2011): Neonatal jaundice in low- and middleincome countries. In: Stevenson DK, Maisels J, Watchko J. Care of the jaundiced neonate.chapter13, p 263-73.

[3] Radmacher PG, Groves FD, Owa GA, Gabriel EO and Amuabunos EA (2015):licensee BioMed Central, Bilirubin-induced neurologic dysfunction algorithm is useful in evaluating severity of jaundice in a resource-limited setting.15:28.10.1186/s12887-015-03552.

[4] Bansal A, Jain S and Parmar V.R. (2010):bilirubin rebound after phototherapy for neonatal jaundice Indian Pediatrics Vol. 47 Issue 7, p60760.

[5] Mreihil K, Mcdonagh A, Nakstad B and Hansan T (2010): Early Isomerization of Bilirubin in phototherapy of neonatal jaundice, Pediatr Res; 67(6):656-659.

[6] Abd-Ellatif MA and Abd-Ellatif DA (2012): The use of intensive phototherapy in severe neonatal hyperbilirubinemia. J Egypt Soc Parasitol; 42(2):483-94.

[7] Iskander I, Gamaleldin R, El Houchi S, El Shenawy A, Seoud I, El Gharbawi $\mathbf{N}$, Abou-Youssef H, Aravkin A and Wennberg RP (2014): Serum bilirubin and bilirubin/albumin ratio as predictors of bilirubin encephalopathy;134(5):e1330-9.

[8] Davutoğlu M, Garipardiç M, Güler E, Karabiber $H$ and Erhan D (2010): The etiology of severe neonatal hyperbilirubinemia and complications of exchange transfusion, Turk J Pediatr;52(2):163-6.

[9] De Carvalho M, Mochdece CC, Moura CA and Moreira ME (2011): Highintensity phototherapy for the treatment of severe nonhaemolytic neonatal hyperbilirubinemia, Acta Pædiatrica; 100, pp. 620-623.

[10] Al-Hafidh J, Barquinero JF, Lindholm C, Moquet J, Perälä $M$, Roch-Lefèvre S, Scherthan $H$, Thierens H, Vral A and Vandersickel V (2013): Manual versus automated $\gamma-\mathrm{H} 2 \mathrm{AX}$ foci analysis across five European laboratories: can this assay be used for rapid biodosimetry in bilisphire radiation. Mutat Res;756 (12):170-3.

[11] Umran M (2012): Neonatal Jaundice due to G6PD Deficiency, Pakistan Pediatric J; VIII (3):126-128.

[12] Gamaleldin R, Iskander I, Seoud I, Aboraya H, Aravkin A, Sampson PD and Wennberg RP (2011): Risk factors for neurotoxicity in newborns with sever neonatal hyperbilirubinemia. Pediatrics; 128(4):925-31.

\section{[13] Steiner LA, Bizzarro} MJ, Ehrenkranz RA and Gallagher PG (2007): A decline in the frequency of neonatal exchange transfusions and its effect on exchange-related mobidity and mortality, Pediatrics; 120:27-30. 